\title{
Non-thermal Production of Natural betalain Colorant Concentrate from Red Beet Extract by Using the Osmotic Distillation
}

\author{
Nazanin Amirasgari ${ }^{1}$, Hossein Mirsaeedghazi ${ }^{2 *}$ \\ 1- Dept.of Food Science and Technology, Science and Research Branch, Islamic Azad University, Mazandaran, Iran. \\ 2- Dept.of Food Technology Engineering, College of Abouraihan, University of Tehran, Pakdasht, Iran.
}

\section{A B S T R A C T}

Background and Objectives: Red beet extract concentrate can be used as a natural colorant in food products; however, destructive effects of thermal methods to produce juice concentrate decrease nutritional value in the final product.

Materials and Methods: In this study, red beet extract was concentrated using osmotic distillation method, and the best pretreatment was evaluated to increase the efficiency of the concentration process. Also changes in some physicochemical properties such as betacyanins and betaxanthins contents, total phenolic compounds and antioxidant activity of red beet juice were evaluated by both the membrane and thermal concentration methods.

Results: The results showed that the best concentration efficiency was obtained after pretreatment of the fresh juice with centrifugation at $1699 \mathrm{G}$ for $17 \mathrm{~min}$. Evaluation of the effect of both the membrane and thermal concentration processes on the physicochemical properties of juice showed that the membrane method did not change betacyanin and betaxanthin contents, total phenolic compounds, and antioxidant activity of the red beet extract. However, these properties decreased with the thermal concentration method by 26, 15, 11 and 13\%, respectively.

Conclusions: According to the results, osmotic distillation can produce red beet concentrate with more nutritional value than the concentrate produced with thermal method.

Keywords: Membrane, Natural betalain colorant, Osmotic distillation, Red beet

\section{Introduction}

Red beet (Beta vulgaris L.) has high nutritional value due to its high antioxidant activity, which can make it useful to prevent chronic diseases such as cancer and cardiovascular diseases (1-3) and other age related diseases (4). Studies have shown that red beet has an antioxidant activity 10 times more than vegetables (1). Also large amount of B vitamin is found in this vegetable, which is capable of preventing heart diseases (5). Phenolic compounds and betalain pigments cause health related properties in red beet such as anti-viral, and anti-cancer properties $(1,4)$. Furthermore, anti-inflammatory effects have been reported for betalain pigments in red beet root $(3,6)$.

Red beet's color is caused by betalain $(1,3,7)$, which is soluble in water (7) and in the form of powder or concentrate can be used as a natural colorant additives in foods such as ice cream, powder drinks, soup, and bacon products. It can also be used in medicine (8). So red beet extract concentrate is widely used in food industries (9). Low water activity in the concentrate prevents the growth of microorganisms and increases the shelf life of juices $(3,10)$. Concentration process can further decrease production costs, as well as packaging and storage 
requirements (10). Thermal treatment is the common method to produce juice concentrates (3); however, betalain is sensitive to heat treatment $(3,11)$. As a result, food color and its antioxidant activity change after thermal processing (3). Hence, it is necessary to find a safe method to concentrate heat sensitive foods such as red beet extract.

Currently, osmotic distillation (OD) has been introduced as a new membrane technique to concentrate the heat-sensitive fruit juices (12-15). The process is carried out at room temperature and normal pressure $(12,16,17)$; therefore, it is expected that OD causes minimal chemical destruction (12, 18). It is reported that this method is able to preserve nutrients and organoleptic properties in concentrated fruit juices and natural colors (19). This method is based on the vapor pressure difference between the two phases with different concentrations, which are separated with a hydrophobic membrane $(20,21)$. Juice as the feed and brine as the stripping solution move in each side of the membrane, and the stripping solution is diluted. Since the water vapor passes through the membrane so the juice is concentrated $(10,22,23)$.

There are several studies to prevent betalain in red beet extract. Sturzoiu et al. (24) investigated and analyzed the extraction of betanine from red beet with different solvents. They also investigated the effect of various parameters on the extraction rate and stability of betanine. The results showed that the extractions with anaqueous solution of citric acid $0.2 \%$ and ascorbic acid $0.1 \%$ and an aqueous solution of ethanol $20 \%$ and ascorbic acid $0.5 \%$ were the most efficient. Also 10 min was introduced as the best extraction time.

Different fruit juices such as orange, apple and kiwi were undergone OD to concentrate (20). Cassano et al. (16) concentrated blood orange juice using OD after clarification with ultrafiltration and pre-concentration with reverse osmosis. The results showed that antioxidant activity, juice color and aroma decreased after thermal concentration while no reduction was observed in the concentration process with OD. Same results were obtained by Galaverna et al. (20). In addition, the antioxidant activity of pomegranate juice was preserved in the concentration process with OD (13).
The aim of this work is the application of OD process to produce concentrated red beet extract with high nutritional value. It helps us to introduce a good source of natural colorant to be used in food industries. Hence, different physicochemical properties of red beet juice were evaluated before and after both membrane and thermal concentration methods to compare these two methods.

\section{Materials and Methods}

Preparation of red beet extract: Red beet (Dark red Detroit vt.) extract was obtained from a domestic juicer (PARS KHAZAR JC-700P, IRAN). Four samples were prepared for concentration; they included the initial extract (without clarification process), the extract clarified with centrifugation at $15291 \mathrm{G}$ for $5 \mathrm{~min}$, the extract, clarified with centrifugation at $1699 \mathrm{G}$ for $17 \mathrm{~min}$, and the extract clarified with centrifugation at $15291 \mathrm{G}$ for $5 \mathrm{~min}$ followed by microfiltration.

Osmotic distillation unit: OD process was performed in a laboratory scale unit at counter current mode. Hydrophobic polyvinylidene fluoride (PVDF) membrane (Millipore, USA) with the active area of $131.75 \mathrm{~cm}^{2}$ was used. Calcium chloride solution was used as brine, which was concentrated with the evaporator to fix its concentration. Brine solution was inserted on a digital balance (EK-1500, A\&D Company, Japan) to measure water vapor flux in the membrane process. Both brine and juice were recycled with separate peristaltic pump.

Evaluation of the physicochemical properties of red beet extract: A portable refractometer (ATAGO, HSR-500, Japan) and a portable turbidimeter (TU-2016, Lutron Electronic, Taiwan) were used in order to measure total soluble solid content (expressed as ${ }^{\circ}$ Brix) and juice turbidity (expressed as NTU) at room temperature, respectively. Total solid content of red beet juice was measured after removing the water in the incubator. Hunter lab (Hunter lab Associates Laboratory Inc., Reston, VA, USA) was used for measuring $a^{*}, b^{*}$ and $\mathrm{L}^{*}$ parameters to evaluate the color of red beet juice. According to Ravichandran et al. [3], betalain pigments were measured with recording their absorbance in the spectrophotometer (CAMBDA 25 US/VIS, Perkin Elmer, USA) at $476 \mathrm{~nm}$ (for betaxanthins) and $538 \mathrm{~nm}$ (for betacyanins) after 
adjusting the $\mathrm{pH}$ to 6.5 with phosphate buffer. Colorant pigment content $\left(\mathrm{B}_{\mathrm{c}}, \mathrm{mgl}^{-1}\right)$ was calculated using Eq. 1 as follows:

$B_{C}=\frac{A \times D F \times M W \times 1000}{e \times l}$

Where, A, DF, 1, MW and e are absorption, dilution factor, path length of the cuvette, molecular weights and molar extinction coefficients, respectively. Phenolic compounds were measured according to Georgiev et al. (6), and the result was expressed as mg ferulic acid per $100 \mathrm{ml}$ juice. According to Mirsaeedghazi et al. (26), antioxidant activity in the samples was determined using 2, 2diphenyl -1-picrylhydrazyl (DPPH) method, and its value was expressed as EC50, which is concentration of the juice sample that remains 50\% of DPPH. The rejection factor was calculated according to Eq. 2:

Rejection factor $=\frac{\left|\varphi_{f}-\varphi_{p}\right|}{\varphi_{f}}$

where, $\varphi_{f}$ and $\varphi_{p}$ are the values of each characteristic before and after membrane clarification, respectively.
Statistical analysis: All treatment combinations were performed in three repetitions, and the means were reported. Statistical analysis of the data was performed using one-way Analysis of Variance (ANOVA), and the mean values were compared by applying Duncan's multiple range tests using Minitab 15 software $(\mathrm{P}<0.05)$.

\section{Results}

Concentration of non-clarified extract: One of the most important parameters in OD process is determination of the flow rates of both feed and salt solutions. Therefore, 8 patterns were selected to find the most efficient flow rate where the feed and brine flow rates were $0.66-1.7 \mathrm{ml} / \mathrm{s}$ and $0.56-1.77 \mathrm{ml} / \mathrm{s}$, respectively. The results showed that the total soluble solid content (TSS) of red beet juice increased over time, which caused increasing the weight of salt solution (Figs. 1 and 2). Although the TSS of red beet juice generally had an increasing trend; however, it remained stable after a certain time. Also the results showed that two different combinations namely a combination with the juice flow rate of $1.70 \mathrm{ml} / \mathrm{s}$ and the brine flow rate of 0.56 $\mathrm{ml} / \mathrm{s}$, and a combination with the juice flow rate of $0.66 \mathrm{ml} / \mathrm{s}$ and the brine flow rate of $0.56 \mathrm{ml} / \mathrm{s}$ had the best efficiency.

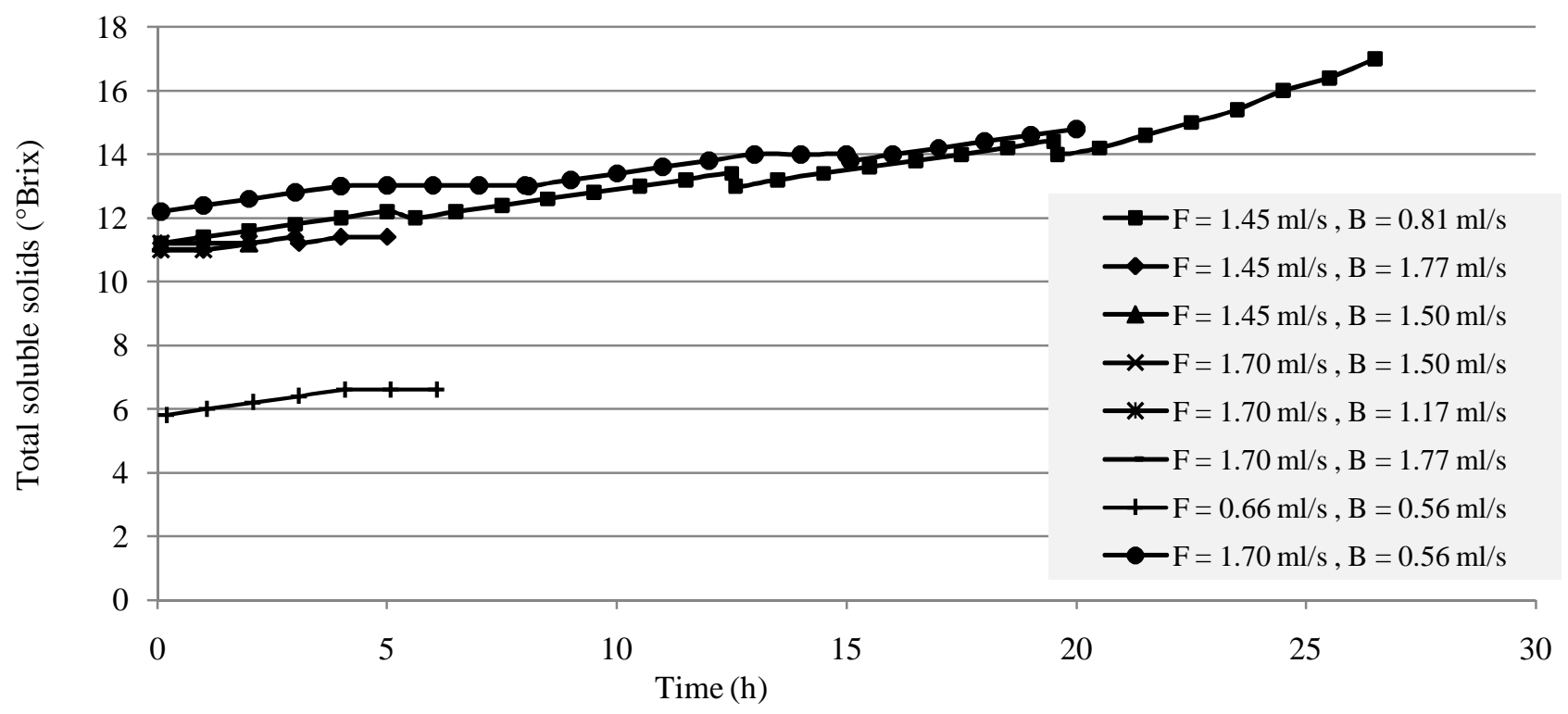

Fig. 1. Changes in the total soluble solids of initial red beet juice (without clarification) during concentration using osmotic distillation ( $\mathrm{F}=$ juice flow rate, $\mathrm{B}=$ brine flow rate). 


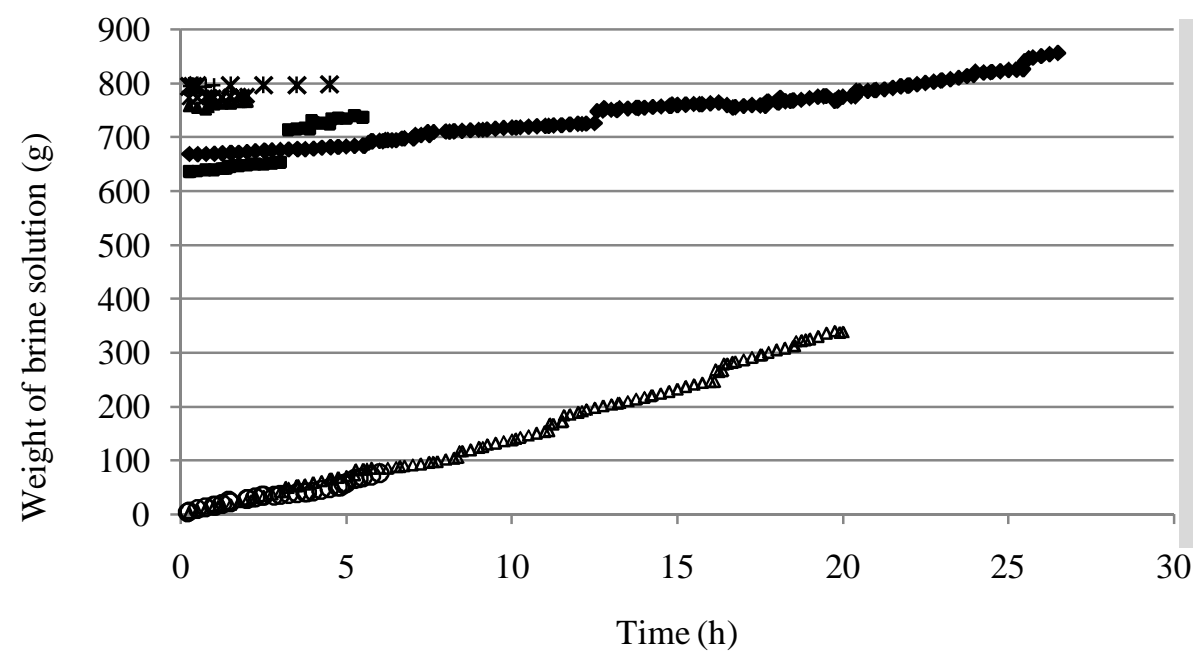

- $\mathrm{F}=1.45 \mathrm{ml} / \mathrm{s}, \mathrm{B}=0.81 \mathrm{ml} / \mathrm{s}$

- $\mathrm{F}=1.45 \mathrm{ml} / \mathrm{s}, \mathrm{B}=1.77 \mathrm{ml} / \mathrm{s}$

$\Delta \mathrm{F}=1.45 \mathrm{ml} / \mathrm{s}, \mathrm{B}=1.50 \mathrm{ml} / \mathrm{s}$

$\times \quad \mathrm{F}=1.70 \mathrm{ml} / \mathrm{s}, \mathrm{B}=1.50 \mathrm{ml} / \mathrm{s}$

$+\mathrm{F}=1.70 \mathrm{ml} / \mathrm{s}, \mathrm{B}=1.17 \mathrm{ml} / \mathrm{s}$

* $\mathrm{F}=1.70 \mathrm{ml} / \mathrm{s}, \mathrm{B}=1.77 \mathrm{ml} / \mathrm{s}$

○ $F=0.66 \mathrm{ml} / \mathrm{s}, \mathrm{B}=0.56 \mathrm{ml} / \mathrm{s}$

$\Delta \quad \mathrm{F}=1.70 \mathrm{ml} / \mathrm{s}, \mathrm{B}=0.56 \mathrm{ml} / \mathrm{s}$

Fig. 2. Changes in stripping solution weight during the concentration of initial red beet juice (without clarification) using osmotic distillation ( $\mathrm{F}=$ Juice flow rate, $\mathrm{B}=$ Brine flow rate).

\section{Concentration of the red beet juice clarified with} centrifugation: Red beet extract was clarified using the centrifugation process in order to remove large particles causing membrane fouling. The results showed that the efficiency of the concentration process of red beet extract after centrifugation at $15291 \mathrm{G}$ for $5 \mathrm{~min}$ was more than the efficiency value for the non-clarified extract (Figs. 3-4).

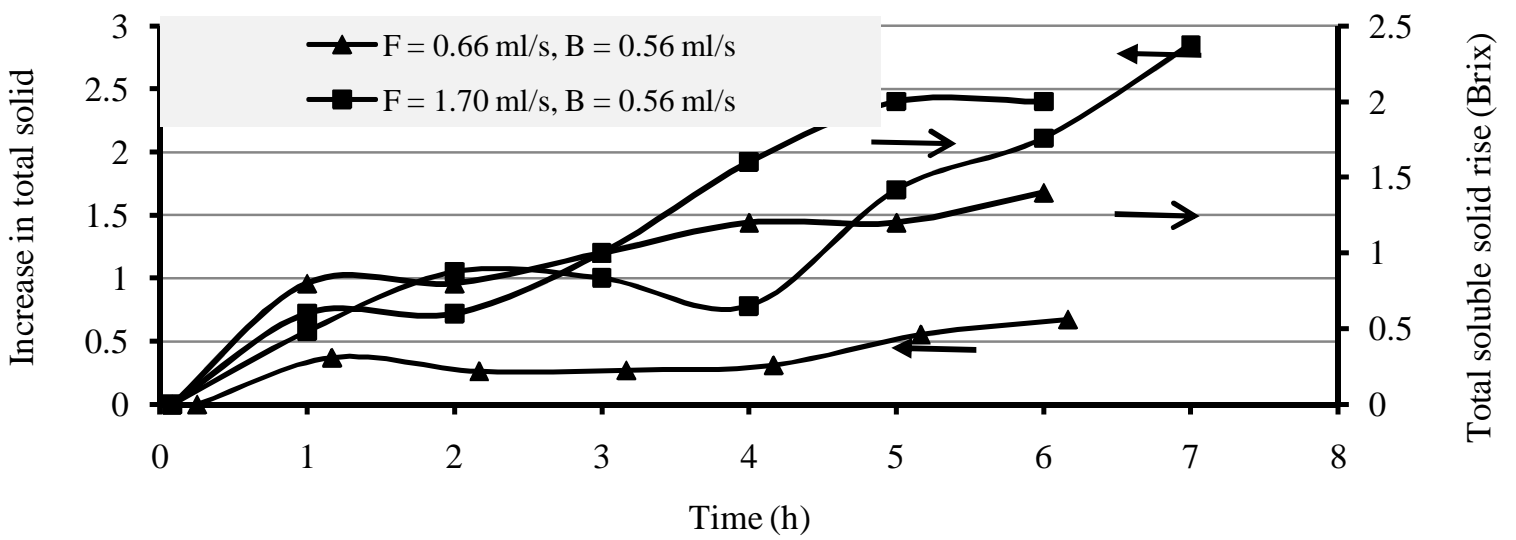

Fig. 3. Changes in the total soluble solids and total solid content of red beet juice (clarified with centrifugation at $15291 \mathrm{G}$ for $5 \mathrm{~min}$ ) during the concentration process ( $\mathrm{F}=$ Juice flow rate, $\mathrm{B}=$ Brine flow rate).

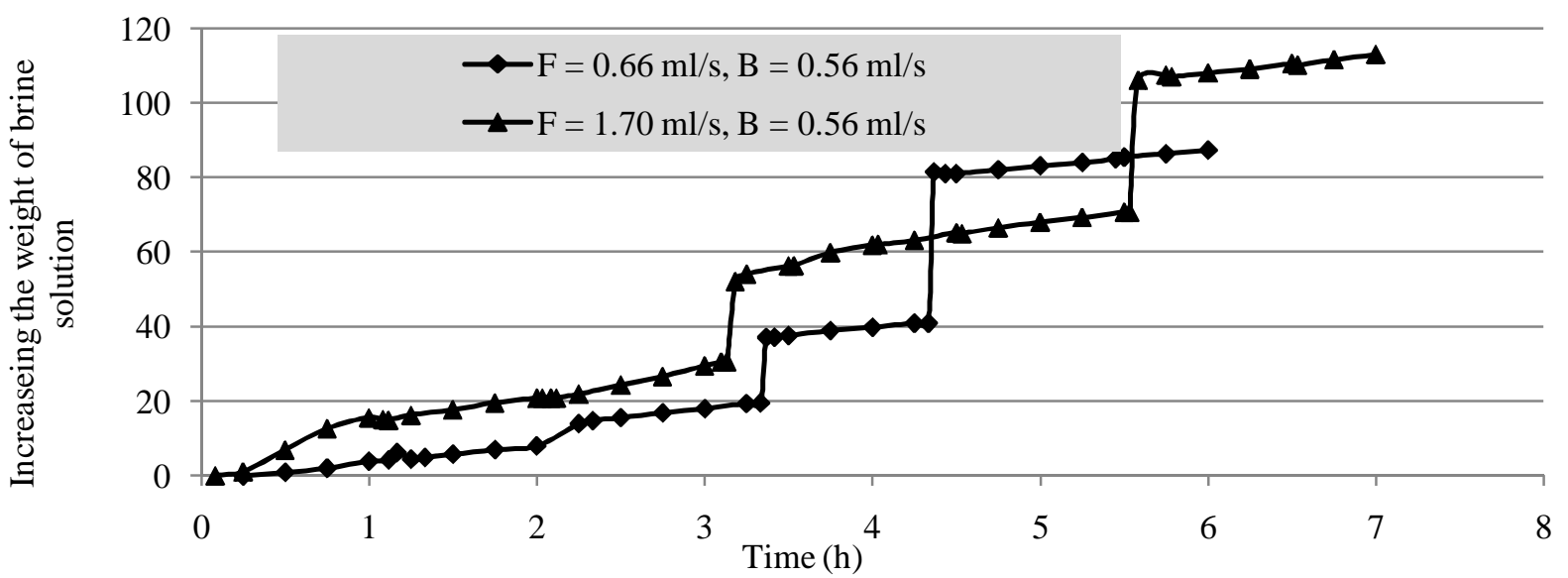

Fig. 4. Changes in the weight of stripping solution during the concentration process (clarified with centrifugation at $15291 \mathrm{G}$ for $5 \mathrm{~min}$; $\mathrm{F}$ =Juice flow rate, $\mathrm{B}=$ Brine flow rate). 
Then the centrifugation conditions were changed to $1699 \mathrm{G}$ for $17 \mathrm{~min}$ and the concentration process was performed after this process. It was revealed that during the first two hours, the TSS of red beet juice increased by about $1{ }^{\circ}$ Brix; however, low concentration rate was observed after the early stage of process, which was solved after membrane alternatively washing. Red beet extract was concentrated from 12 to $30^{\circ}$ Brix using the above membrane set up (Figs. 5 and 6). The low amount of feed volume was a limitation, which did not allow us to continue the juice concentration process.

\section{Concentration of red beet juice after clarification}

with microfiltration process: At the last experiment, red beet extract was treated with centrifugation at $15291 \mathrm{G}$ for $5 \mathrm{~min}$ and then, it was clarified using microfiltration. The clarified extract undergone concentration process using OD. The finding revealed lower increasing for TSS than the values for the previous treated extract. The same behavior was seen for increasing the total solid content in red beet extract; so that the total solid and TSS contents changed (Figs. 6, 7).

Changes in physicochemical properties: The red beet extract was centrifuged at $1699 \mathrm{G}$ for $17 \mathrm{~min}$ and concentrated to $30^{\circ}$ Brix. Then its physicochemical properties were evaluated (Table 1).

Similar concentration process was performed using the thermal processing. Both of the concentrated juices were diluted to $12{ }^{\circ}$ Brix (initial TSS of fresh red beet juice) to evaluate the net effect of the concentration process.

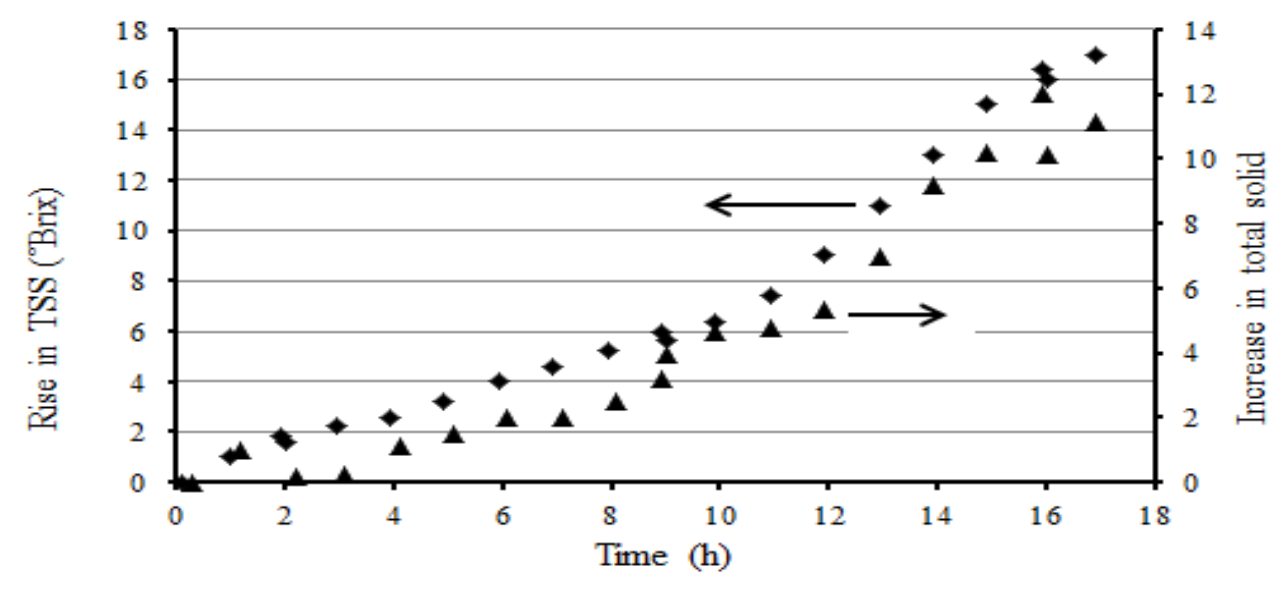

Fig. 5. Changes in total soluble solids (TSS) and total solid contents (clarified with centrifugation at $1699 \mathrm{G}$ for $17 \mathrm{~min}$; Juice flow rate $=1.70 \mathrm{ml} / \mathrm{s}$, Brine flow rate $=0.56 \mathrm{ml} / \mathrm{s}$ ).

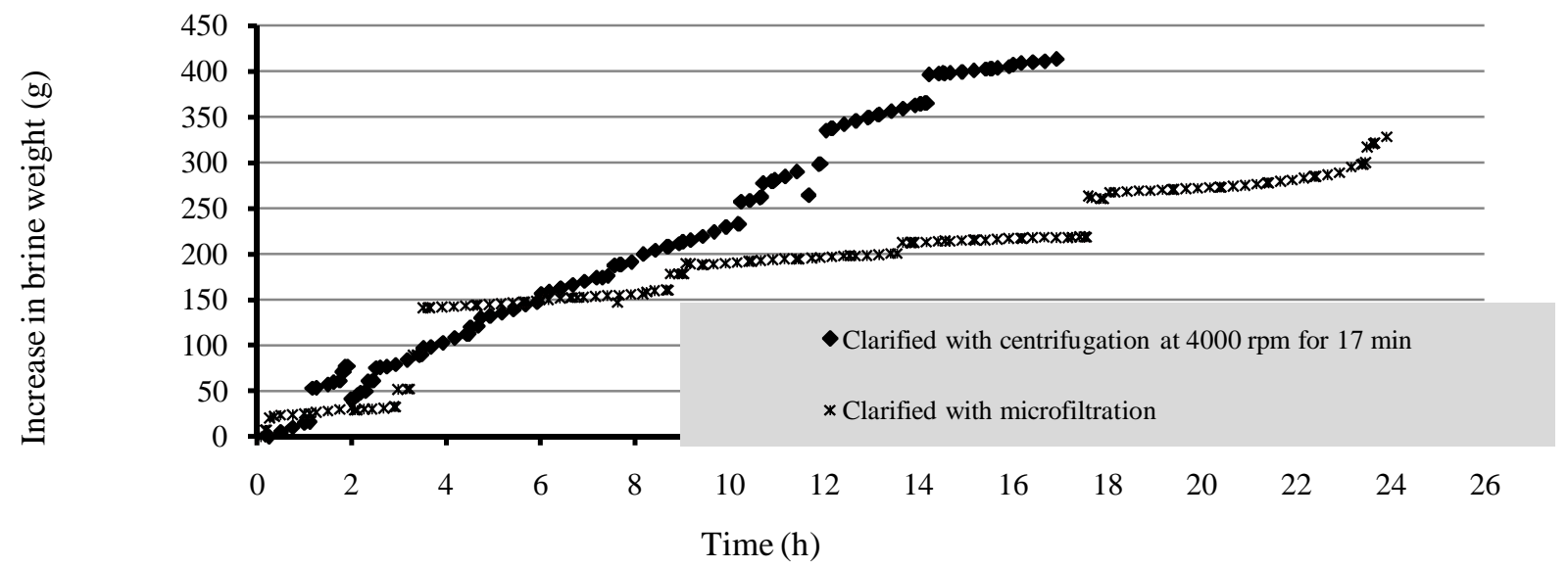

Fig. 6. Changes in the weight of stripping solution during the concentration of red beet juice (Juice flow rate $=1.70 \mathrm{ml} / \mathrm{s}$, Brine flow rate $=0.56 \mathrm{ml} / \mathrm{s})$. 


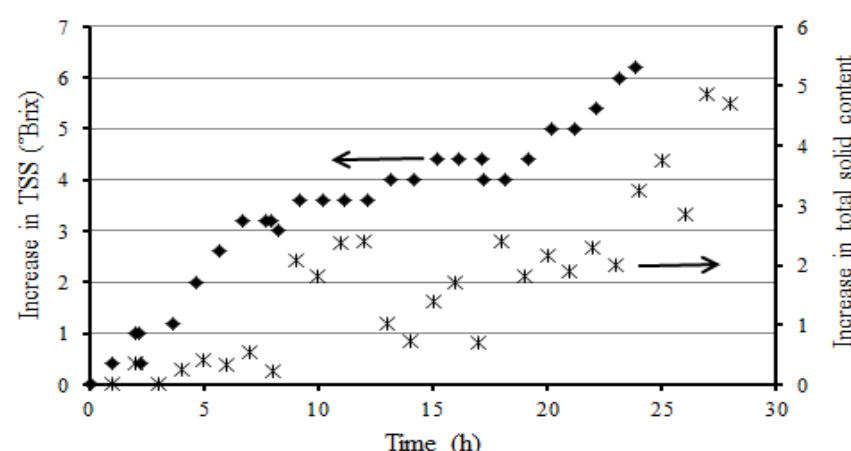

Fig.7. Changes in the total soluble solid (TSS) and total solid contents of red beet juice (clarified with microfiltration) during concentration (juices flow rate $=1.70 \mathrm{ml} / \mathrm{s}$, brine flow rate $=0.56 \mathrm{ml} / \mathrm{s}$ )

Two different main betalain pigments in the red beet extract (namely betacyanins and betaxanthins) were preserved in the membrane concentration process; however, they were reduced after thermal concentration due to heat sensitivity of these pigments $(3,11)$. A similar result was observed for total polyphenol content, which shows its thermal destruction. As expected, the constant values of betacyanins, betaxanthins and polyphenols resulted a fixed value of antioxidant activity; however, the antioxidant activity of red beet extract was decreased after thermal concentration.

The $\mathrm{L}^{*}$ value indicates luminosity of the red beet extract, which increased in both the membrane and thermal concentration processes; however, the amount of $\mathrm{L}^{*}$ increasing in the process was higher than in the membrane process. Also the value of $a^{*}$ indicates reddish color of the red beet juice. The same behavior was observed for the value of reddish color as luminosity. On the other hand, thermal concentration process could increase both the luminosity and reddish color of red beet juice more than the OD method. Yellowish color of juice was indicated by the value of $b^{*}$, which was decreased after the membrane concentration process though its value was increased after the thermal concentration process. Evaluation of juice turbidity showed that both of the concentration methods increased the juice turbidity; however, this increase in the thermal process was much more than in the membrane process.

Table 1. Changes in the physicochemical properties of red beet juice before and after the concentration process

\begin{tabular}{|c|c|c|c|c|c|c|c|}
\hline & & \multicolumn{3}{|c|}{ Osmotic distillation } & \multicolumn{3}{|c|}{ Thermal concentration } \\
\hline & & $\begin{array}{l}\begin{array}{l}\text { Fresh } \\
\text { juice }\end{array} \\
\end{array}$ & $\begin{array}{c}\text { Reconstructed } \\
\text { juice }\end{array}$ & $\begin{array}{l}\text { Rejection } \\
\text { factor }\end{array}$ & $\begin{array}{l}\begin{array}{l}\text { Fresh } \\
\text { juice }\end{array} \\
\end{array}$ & $\begin{array}{c}\text { Reconstructed } \\
\text { juice }\end{array}$ & $\begin{array}{c}\text { Rejection } \\
\text { factor }\end{array}$ \\
\hline \multicolumn{2}{|c|}{ Betacyanins (mg/l) } & $50.8 \pm 2.3$ & $50.6 \pm 1.2$ & $0^{\mathrm{b}, *}$ & $52.8 \pm 2.1$ & $39.3 \pm 0.9$ & $0.26^{\mathrm{a}}$ \\
\hline \multicolumn{2}{|c|}{ Betaxanthins(mg/l) } & $32.6 \pm 2.4$ & $33.9 \pm 3.8$ & $0^{\mathrm{b}}$ & $33.0 \pm 0.0$ & $28.0 \pm 0.8$ & $0.15^{\mathrm{a}}$ \\
\hline \multicolumn{2}{|c|}{$\begin{array}{l}\text { Total phenolic compounds } \\
\text { (mg ferulic acid } / 100 \mathrm{ml} \text { ) }\end{array}$} & $89.2 \pm 0.4$ & $89.8 \pm 0.3$ & $0^{\mathrm{b}}$ & $115.4 \pm 2.7$ & $102.4 \pm 3.0$ & $0.11^{\mathrm{a}}$ \\
\hline \multicolumn{2}{|c|}{ EC50 (ml juice/gr DPPH) } & $114.4 \pm 2.7$ & $112.4 \pm 1.0$ & $0^{\mathrm{b}}$ & $543.9 \pm 9.7$ & $615.5 \pm 6.2$ & $0.13^{\mathrm{a}}$ \\
\hline \multirow{3}{*}{ Color } & $\mathrm{L}^{*}$ & $2.86 \pm 0.13$ & $3.57 \pm 0.01$ & $0.25^{\mathrm{b}}$ & $2.86 \pm 0.13$ & $7.78 \pm 0.2$ & $1.72^{\mathrm{a}}$ \\
\hline & $a^{*}$ & $4.98 \pm 0.00$ & $14.15 \pm 0.25$ & $1.84^{\mathrm{b}}$ & $4.98 \pm 0.00$ & $23.65 \pm 0.02$ & $3.95^{\mathrm{a}}$ \\
\hline & $b^{*}$ & $2.94 \pm 0.18$ & $0.51 \pm 0.19$ & $0.83^{\mathrm{b}}$ & $2.94 \pm 0.18$ & $6.05 \pm 0.15$ & $1.06^{\mathrm{a}}$ \\
\hline \multicolumn{2}{|c|}{ Turbidity (NTU) } & $785 \pm 2$ & $797 \pm 3$ & $0.01^{\mathrm{b}}$ & $168 \pm 3$ & $226 \pm 5$ & $0.34^{\mathrm{a}}$ \\
\hline
\end{tabular}

** Mean values were reported and similar letters in each row for rejection factors show insignificant difference between the values $(\mathrm{P}<0.05)$.

\section{Disc ussion}

The TSS of red beet juice was stable after a certain time during OD process of non-clarified extract due to deposition of large particles on the membrane surface which led to membrane fouling. Similar result was obtained by Johnson and $\mathrm{Xu}$ (27) who showed membrane fouling during the concentration of whole milk. The membrane fouling was partly removed using washing with water, and the concentration process continued after membrane cleaning.

Our observations confirmed the sedimentation of color compounds in the feed tank during the concentration process. It is probably due to the application of pressure in the microfiltration process that causes some of the compounds to be unstable. They are deposited during the OD process and 
missed; this leads to change in the total solid and TSS contents. In the present work, the red beet juice showed different behavior compared to what reported by Johnson and $\mathrm{Xu}$ who concluded that microfiltration can increase juice concentration (27).

Application of OD process was desirable to preserve nutritional value of red beet extract during its concentration process. Betacyanins, betaxanthins and antioxidant activity of red beet juice did not change after membrane processing; however they reduced after thermal concentration. Reduction of antioxidant activity in thermal concentration process was due to reduction in the content of both betalains and polyphenol (higher value of EC50 shows lower value of antioxidant activity). Cassano et al. (16) showed that antioxidant activity of citrus and carrot juices decreased after thermal processing.

The present research findings revealed that the OD could produce red beet concentrate with more nutritional value than the concentrate produced with thermal method. Due to experimental limitation (little membrane area), the OD increased juice TSS up to 30. However, it is expected that larger membranes are able to increase the red beet juice's TSS up to higher Brix degrees. Also pretreatment of the red beet extract with centrifugation at $1699 \mathrm{G}$ for 17 min could increase the efficiency of the concentration process due to reducing the fouling phenomenon in the OD.

\section{Financial disclosure}

The authors declared no financial interest.

\section{Funding/Support}

The study did not receive any financial support.

\section{References}

1. Netzel M, Stintzing FC, Quaas D, Strab G, Carle R, Bitsch R, et al. Renal excretion of antioxidative constituents from red beet in humans. Food Res Int 2005; 38: 1051-1058.

2. Frank T, Stintzing FC, Carle R, Bitsch I, Quaas D, Stra BG, et al. Urinary pharmacokinetics of betalains following consumption of red beet juice in healthy humans. Pharmacol Res 2005; 52: 290-297.

3. Ravichandran K, Saw NMMT, Mohdaly AAA, Gabr AMM, Kastell A, Riedel H, Cai Z, et al. Impact of processing of red beet on betalain content and antioxidant activity. Food Res Int 2013; 50: 670-675.

4. Ravichandran K, Ahmed AR, Knorr D, Smetanska I. The effect of different processing methods on phenolic acid content and antioxidant activity of red beet. Food Res Int 2012; 48: 16-20.

5. Wang M, Goldman IL. Accumulation and distribution of free folic acid content in red beet (Beta vulgaris L.). Plant Foods Hum Nutr 1997; 50: 1-8.

6. Georgiev VG, Weber J, Kneschke EM, Denev PN, Bley T, Pavlov AI. Antioxidant activity and phenolic content of betalain extracts from intact plants and hairy root cultures of the red beetroot beta vulgaris cv. Detroit dark red. Plant Food Hum Nutr 2010; 65: 105-111.

7. Czapski J, Mikolajczyk K, Kaczmarek M. Relationship between antioxidant capacity of red beet juice and contents of its betalain pigments. Pol J Food Nutr Sci 2009; 59: 119-122.

8. Fernández-López JA, Angosto JM, Giménez PJ, León G. Thermal Stability of Selected Natural Red Extracts Used as Food Colorants. Plant Foods Hum Nutr 2013; 68: 11-17.

9. Ravichandran K, Palaniraj R, Saw NMMT, Gabr AMM, Ahmed AR, Knorr D, et al. Effects of different encapsulation agents and drying process on stability of betalains extract. J Food Sci Technol 2012; in press.

10. Cassano A, Conidi C, Timpone R, Avella MD, Drioli E A membrane-based process for the clarification and the concentration of the cactus pear juice. J Food Eng 2007; 80: 914-921.

11. Stintzing FC, Carle R. Functional properties of anthocyanins and betalains in plants, food, and in human nutrition. Trends Food Sci Technol 2004; 15: 19-38.

12. Cassano A, Jiao B, Drioli E. Production of concentrated kiwifruit juice by integrated membrane process. Food Res Int 2004; 37: 139-148.

13. Cassano A, Conidi C, Drioli E. Clarification and concentration of pomegranate juice (Punicagranatum L.) using membrane processes. J Food Eng 2011; 107: 366373.

14. Hongvaleerat C, Cabral LMC, Dornier M, Reynes M, Ningsanond S. Concentration of pineapple juice by osmotic evaporation. J Food Eng 2008; 88: 548-552.

15. Valdés H, Romero J, Saavedra A, Plaza A, Bubnovich V. Concentration of noni juice by means of osmotic distillation. J Membr Sci 2009; 330: 205-213.

16. Cassano A, Drioli E, Galaverna G, Marchelli R, Di Silvestro G, Cagnasso P. Clarification and concentration of citrus and carrot juices by integrated membrane processes. J Food Eng 2003; 57: 153-163.

17. Rektor A, Vatai G, Békássy-Molnár E. Multi-step membrane processes for the concentration of grape juice. Desalination 2006; 191: 446-453.

18. Cassano A, Figoli A, Tagarelli A, Sindona G, DRIOLI, E. Integrated membrane process for the production of highly nutritional kiwifruit juice. Desalination 2006; 189: 21-30. 
19. Babu BR, Rastogi NK, Raghavarao KSMS. Mass transfer in osmotic membrane distillation of phycocyanin colorant and sweet-lime juice. J Membr Sci 2006; 272: 58-69.

20. Galaverna G, Silvestro GD, Cassano A, Sforza S. A new integrated membrane process for the production of concentrated blood orange juice: Effect on bioactivecompounds and antioxidant activity. Food Chem 2008; 106: 1021-1030.

21. Thanedgunbaworn R, Jiraratananon R, Nguyen $\mathrm{MH}$. Mass and heat transfer analysis in fructose concentration by osmotic distillation process using hollow fibre module. J Food Eng 2007; 78: 126-135.

22. Jiao B, Cassano A, Drioli, E. Recent advances on membrane processes for the concentration of fruit juices: A review. J Food Eng 2004; 63: 303-324.

23. Wang L, Min J. Modeling and analyses of membrane osmotic distillation using non-equilibrium thermodynamics. J Membr Sci 2011; 378: 462-470.
24. Sturzoiu A, Stroescu M, Stoica A, Dobre T. Betanine extraction from beta vulgaris-experimental research and statistical modeling. UPB Sci Bull, Series B 2011; 73: 145-156.

25. Nemzer B, Pietrzkowski Z, Spórna A, Stalica P, Thresher W, Michałowski T, et al. Betalainic and nutritional profiles of pigment-enriched red beet root (Beta vulgaris L.) dried extracts. J Food Chem 2011; 127: 42-53.

26. Mirsaeedghazi H, Emam-Djomeh Z, Mousavi S M. Clarification of pomegranate juice by microfiltration with PVDF membranes. Desalination 2010; 264: 243 248.

27. Johnson B, Xu J. Fabrication of osmotic distillation membranes for feeds containing surface-active agents. Queensland University of technology, School of Physical and Chemical Sciences 2004. 